\title{
Pode o Inseto "des-fazer" um Mundo? O Bicudo e a (contra)colonização da Monocultura no Semiárido da Paraíba ${ }^{1}$
}

\author{
Gabriel Holliver ${ }^{1}$ \\ ${ }^{1}$ Museu Nacional do Rio de Janeiro, Rio de Janeiro, RJ, Brasil
}




\section{Resumo}

O presente artigo, baseado em um engajamento etnográfico junto a famílias de agricultores camponeses do Médio Sertão da Paraíba, realizado desde 2015, se propõe a narrar a ascensão e o declínio das plantations de algodão no semiárido da Paraíba. No centro da narrativa, se encontra o bicudo (Anthonomus grandis), um inseto nunca antes visto na região, que surgiu em meio às plantações no início da década de 1980 e gerou uma inflexão histórica, desmantelando o então vigente sistema agrícola de monocultura que impedia a prática da agricultura tradicional local. Com ação de magnitude revolucionária, o bicudo terminou por promover uma difusa descentralização fundiária, permitindo a atualização de práticas agrícolas tradicionais até então submersas. Assim, por meio de uma narrativa diacrônica, realizo o contraste entre dois sistemas agrícolas, a agrobiodiversidade neles presentes, seus modos de se relacionar com a terra e os efeitos práticos promovidos por tais atividades na textura da paisagem.

Palavras-chave: Plantation. Bicudo. Agricultores Experimentadores. Conhecimento Tradicional. Agrobiodiversidade.

\section{Abstract}

The present article, based in an ethnographical engagement among peasant's families in the Médio Sertão da Paraíba realized since 2015, proposes to narrate the ascension and decline of the cotton plantations in the Paraiba's semiarid. At the center of this narrative there is the boll weevil (Anthonomus grandis), an insect that had never seen before in the region, whose apprearance amidst crops at the begging of the 1980's generated historical inflection a historical inflection, dismantling the monocultural agricultural system that prevented the local traditional agriculture. With action of revolutionary magnitude, the boll weevil ended up promoting a diffuse fundiary descentralization, allowing the actualization of traditional agricultural practices that remained unused until then. Thus, through a diachronic narrative, I produce the contrast between two agricultural systems, their specific agrobiodiversity, their modes of relating with the earth and the practical effects promoted by these activities in the texture of the landscape.

Keywords: Plantation. Boll Weevil. Agricultores Experimentadores. Traditional Knowledge. Agrobiodiversity. 


\section{Introdução}

Na lenta ética do encontro, não estamos falando de conceitos sobre os quais se escrever (como se fossem exteriores), mas sobre eventos a serem participados e compartilhados, imaginativamente e de outras formas. As próprias histórias têm o potencial de promover entendimentos de éticas incorporadas, relacionais e contingentes. Minha escrita lenta é evocada por eventos dentro do mundo vivido e procura atrair os leitores para uma proximidade ética com esses eventos. ${ }^{2}$ (Deborah Bird Rose)

To presente artigo, pretende-se apresentar um caso etnográfico 1 pertinente para pensar três questões que recentemente têm sido alvo de preocupação por parte da disciplina antropológica, a saber: análise e comparação de sistemas agrícolas (CARNEIRO DA CUNHA, 2017; SANTONIERI, 2015; EMPERAIRE, 2006; 2011), processos de colonização e contracolonização (SANTOS, 2015) e relações multiespecíficas (KIRKSEY; HELMREICH, 2010; TSING, 2015; 2019; VAN DOOREN; KIRKSEY; MÜNSTER, 2016; SUSSEKIND, 2018). No centro do meu argumento, se encontra um inseto, e ele me interessa em especial pela razão de que paralelamente ao fato de ele ser o responsável pelo desmantelamento de um mundo, ao fazê-lo, abrese a possibilidade para que outros mundos possíveis possam emergir. A partir da inflexão histórica provocada por este ator, lanço luz sobre as relações e as transformações sociais na região do Seridó da Paraíba. Em paralelo, estabeleço um confronto entre a agricultura tradicional local e a plantation, seus respectivos modos de lidar com a terra, e os efeitos práticos materializados na paisagem provocados por suas respectivas ações. 
No âmbito da exposição dos fatos apresentados, para oferecer ao leitor uma melhor inteligibilidade da narrativa, a descrição pretende atravessar a socialidade transversalmente por meio de três planos distintos, conectando a experiência no nível da pessoa ao seu caráter coletivo, e ao mesmo tempo que estabelece conexões entre os acontecimentos locais às redes globais mais extensas, busca emaranhar os fatos concernentes àquilo que a antropologia procurou historicamente distinguir entre cultura e natureza.

A ficção persuasiva aqui esboçada, não objetiva refletir a imagem de um 'grupo social', nem oferece um ponto de vista holista que pretende se construir como um relato mais verdadeiro sobre os acontecimentos. É apostando, como Donna Haraway (1995, p. 22 e 24, grifos nossos), na "[...] possibilidade de ver a partir da periferia e dos abismos [...]", com “[...] esperança na transformação dos sistemas de conhecimento e nas maneiras de ver [...]", que adoto uma perspectiva interessada. A partir de um diálogo aliado a determinados corpos situados, busco por meio de conexões e aberturas construir uma narrativa parcial, capaz de perceber os eventos a partir de uma lente curiosa, que nos permita imaginar os acontecimentos de outra forma.

A história que conto é apenas o registro de parte de uma guerra ${ }^{3}$ travada ao longo da história por dois regimes de força e modos de habitar o bioma semiárido brasileiro. Sabe-se que todo o projeto colonizador para região foi, e continua sendo, a determinação material de sua paisagem (MEDEIROS, 2019, p. 26) para integrar essa porção do território nacional à economia capitalista, objetivando combater a seca, elemento particular que o constitui e distingue, através de programas de desenvolvimento que buscam suprimir o atraso e subdesenvolvimento característicos da agricultura de subsistência (TADDEI, 2006) dos povos indígenas ${ }^{4}$ locais. Contudo, seu objetivo nunca se concretizou por completo, porque o objeto com qual as forças colonialistas se depararam, continuamente resistiu e continua a resistir contra as forças transformadoras da história. 
Euclides da Cunha (1905, p. 356), que foi um exímio etnógrafo e descreveu outra batalha dessa guerra entre colonizadores e contra colonizadores, percebeu a importância do "papel das florestas como agente tático precioso". Tanto em Canudos quanto na recente luta pela manutenção dos sistemas agrícolas tradicionais locais, a natureza com seu caráter eminentemente indomesticável ocupou um papel central em resistir as tentativas de controlar a paisagem.

A pouca disponibilidade de água nos rios intermitentes, o sol radiante que não dá trégua nem oferece sombra por debaixo das árvores secas no período de estiagem, os lajeiros reluzentes e a flora impenetrável, composta por uma vegetação hiperxerófila com predominância de espécies espinhosas, compõem o aspecto bélico da paisagem que atacava as tropas militares do Estado. Estas, marchando em um ritmo descompassado, não respeitando a própria velocidade que a natureza os impunha, se viam vulneráveis perante sua singela imponência. Segundo Vargas Llosa (1982), a natureza da caatinga era mais um dos "jagunços" na Guerra do fim do mundo.

Ao contrário das forças alienígenas, aquele povo autóctone que ali habitava tirava proveito da própria convivência ${ }^{5}$ compondo com o meio ambiente em um regime de pensamento que encontrava na vida ao seu entorno um elo de simbiose. Como afirmou Euclides da Cunha em sua grande obra Os Sertões acerca dos diferentes modos de existência extra-humanos que habitam caatinga:

São um aliado incorruptível do sertanejo em revolta. Entram também de certo modo na luta. Armam-se para o combate, agridem. Trançam-se impenetráveis, ante o forasteiro, mas abrem-se em trilhas multívias, para o matuto que ali cresceu. (CUNHA, 1905, p. 357)

No que se segue, apresento outro capítulo recente dessa guerra, agora travada em torno das disputas entre modelos de relação com a ecologia e manejo da paisagem, no qual se estabelecem em lados opostos sistemas agrícolas tradicionais locais e sistemas agrícolas modernos desenvolvimentistas/científicos. 


\section{A Emergência da Monocultura de Algodão e o Mundo do Um}

Desde 2015, realizo pesquisa com agricultores familiares situados no Médio Sertão da Paraíba. Meu trabalho não se concentra em um território bem definido como uma comunidade ou um município, ele é tecido junto a camponeses, que, distribuídos de maneira difusa, têm em comum o fato de se autodenominarem "agricultores experimentadores". Trata-se sobretudo de grandes conhecedores locais, detentores de um saber tradicional acerca da ecologia da caatinga, uma vez que seus modos de existência estão baseados em uma relação intrínseca de convivência com bioma em sintonia com seus respectivos fluxos de alternados períodos de seca e chuva.

Durante a pesquisa que realizei ao longo da graduação (HOLLIVER, 2016) e, posteriormente, no mestrado (HOLLIVER, 2019) ${ }^{6}$, observei algo que era comum a todas as famílias com quem convivi apesar das múltiplas diferenças que se colocavam atualmente entre essas pessoas, suas casas, seus roçados e suas criações. Em um passado recente, todo aquele povo esteve de algum modo engajado no cultivo e na colheita do algodão. Junto a esses agricultores, colhi alguns relatos formando, mediante diferentes perspectivas, um caleidoscópio desse sistema agrícola existente até pouco tempo na região. Assim, eu gostaria de iniciar falando sobre esse tempo que sempre retornava no discurso de meus amigos ${ }^{7}$, pois, a despeito de sua ausência física no presente, o algodão ainda persiste assim como na memória dessa gente, por meio do vazio que ele deixara paisagem.

Desde o início do século XX e até meados da década de 1980, o cultivo do algodão era a principal atividade agrícola e econômica do médio sertão paraibano. Sob os moldes da plantation, sua produção era estruturante e, ainda que atingindo as pessoas de diferentes modos, afetava toda a população, arregimentando como força de trabalho tanto na zona rural, quanto nas pequenas cidades do interior, homens, mulheres e crianças. Para quem lutava nesse serviço, o dinheiro ali apurado 8 era útil tanto para comprar uma roupa para se vestir quanto para cobrir as despesas de rotina. E uma vez que as terras eram dominadas pelo latifúndio, o sistema mais comum era o chamado 
regime de meia, em que o morador com determinada parcela do grande domínio designada sob sua responsabilidade deveria semear, cuidar e colher o algodão, posteriormente repartindo com o proprietário, seu patrão, metade da produção.

No semiárido ocorre uma espécie de algodão conhecida por algodão "mocó" ou "seridó"9 (Gossypium hirsutum L. Marie galante.), de tipo arbóreo com ciclo vegetativo longo, pode permanecer em período produtivo por quase uma década. Como o agricultor Heleno Bento me lembrou, essa variedade é há séculos cultivada na região, sendo inclusive parte dos sistemas agrícolas das etnias que no passado habitavam essas terras, e, em virtude de sua relação histórica com o ambiente do semiárido, ela desenvolveu uma relação de mutualismo com a ecologia local que a tornou adaptada a longos períodos de seca. Mas é apenas na passagem do século XIX ao XX que a cotonicultura ganha dimensões financeiramente produtivas se tornando a base do sustento econômico local. Dotado de fibras longas e morfologicamente resistente à estiagem característica da região, interessava tanto aos grandes proprietários locais, que observavam na espécie uma oportunidade para aferir ganhos econômicos significativos, quanto ao mercado têxtil, pois, como lembra Oswaldo Lamartine (1980, p. 54), “[...] a indústria - dizem os economistas - tem fome de fibras longas".

Tendo como alvo inicial o abastecimento do mercado interno, não demorou para o algodão sertanejo atingir competitividade internacional. Sua notoriedade era tanta que na década de 1930, Campina Grande, cidade do interior paraibano para onde migrava o algodão produzido no Seridó, se tornou a segunda maior comerciante de algodão arbóreo do mundo, perdendo apenas para Liverpool (MORAIS, 2010, p. 18). E, na medida em que se expandiam as plantações, paralelamente ampliava-se o processo de imobilização da mão de obra. Tal situação não se mantinha sem conflitos. A assimetria na relação patrão x empregado, assim como a divisão da safra com acusações recíprocas de roubo eram fontes de constantes polêmicas, fato que para alguns agricultores, essa situação de trabalho era tão degradante que a analogia com a escravidão não lhes é exagerada. Como me disse Seu Inácio Garcia ${ }^{10}$, agricultor que vivenciou o auge da produção de algodão trabalhando como morador: 
No tempo que existia algodão, todo mundo era escravo. Agricultor, pobre, todo mundo era escravo dos proprietários. Começava a cortar algodão no fim do ano, e já começava a fazer aquela conta para fazer a feira, ia atrás daquela arrumação, o proprietário arrumava... Quando ia apanhar o algodão já devia uma contona! Às vezes o pobre fazia a conta no dia que vendia o algodão e ainda ficava faltando um pedaço. Acontecimento [pausa], o peso era de pedra, o proprietário fazia o que queria, recebia o algodão no peso da pedra, mas depois vendia no peso da balança romana e então crescia um bocadão. Mas não tinha essa de repor um quilo para o morador não, era só para ele, uma escravidão triste.

[O agricultor continua]

o pobre vivia agregado feito a bicheira mesmo, quando comprava uma camisa a outra estava rasgada, e o espinhaço era preto, parecia de jumento. Tinha deles que botava apelido no outro, "eita, lá vem fulano! Chega espinhaço de sola!". Não tinha camisa para trabalhar, o pobre coitado, o espinhaço ficava aquela sola. [...] Eu digo porque fui escravo muito tempo, eu e Maria [sua esposa]. A gente apanhava algodão para fazer a feira, quando era no domingo chegava na casa do patrão ele dizia: "hoje não tem dinheiro não, vá na bodega, faça a feira por lá". Pronto, o cabra ia se lascando, fazendo plano perdido, chegava falava com bodegueiro e ele dizia. "rapaz eu vendo, mas só para você pagar porque seu patrão é muito difícil".

O trabalho degradante que o cultivo de algodão impunha não se restringia aos limites da zona rural. Para compreender sua dimensão, a biografia de José Marcelino nos é útil como exemplo. Zé, durante a juventude, presenciou o sofrimento de seu pai trabalhando como meeiro que, mesmo com a ajuda da esposa e dos filhos, não conseguia, com os recursos advindos do labor, sanar as dívidas que era obrigado a contrair para manter a produção. Temendo que seu destino repetisse o de seu pai, o agricultor migrou para a cidade buscando empreender fuga de tal sistema de servidão, mas acabou se engajando em outras atividades ligadas à produção do ouro branco ${ }^{11}$, uma vez que naquele momento havia poucas brechas para ocupações alheias à plantation. Nos tempos de safra, empregava-se nas usinas de beneficiamento, atuando como operário nessa imensa rede que o algodão articulava. $\mathrm{O}$ que não tornava seu serviço menos pesado, pois a jornada de trabalho era igualmente extenuante à rotina na lavoura. 
Falar do algodão é falar de um passado que não agrada muito. [...] algodão só era bom para os patróes, para o morador na verdade não prestava, porque se pagava trator, tinha que pagar veneno. Não pagava trabalhador porque era eu, meu irmão, ele e minha mãe na roça, mas quando chegava no final do ano a gente ficava era devendo ao patrão. [...] Foi passando o tempo, eu fui crescendo e, com determinado tempo, ele já ficando velho [seu pai], eu consegui levar ele para cidade, porque não tinha muito futuro trabalhar de meia. [...] Eu tinha começado a trabalhar no beneficiamento de algodão, que era na usina, só que era pesado também, porque a gente trabalhava doze horas direto. Ai fui para rua e lá continuei trabalhando na usina, só que era de ano em ano né, sendo funcionário.

Tal sistema agrícola necessitava para sua continuidade de um movimento constante de expansão, ao incorporar progressivamente áreas não cultivadas, exigia que ano a ano fossem abertas novas clareiras brocando $^{12}$ a vegetação nativa. Como me contou Heleno Bento:

$\mathrm{Na}$ época do algodão a gente sempre plantava quando desmatava, aproveitava no primeiro ano e plantava milho e feijão consorciado com algodão. Só que a partir do segundo ano em diante, já não plantava mais o milho e o feijão junto com algodão; teria que ter outra área para plantar, porque o algodão cobria e não produzia mais. A gente sempre desenvolvia mais áreas aumentando o roçado por que a gente cultivava o algodão, mas precisava também das culturas de subsistência, o milho, feijão, jerimum, melancia, essas coisas.

Contudo, não seria o caso, claro, de responsabilizar a planta como espécie, pelos efeitos nocivos na paisagem que o algodão deixara. O problema consistiu, antes de tudo, no tipo particular de relação que a plantation com ela estabeleceu. Ao operar por meio de "máquinas de replicação" (TSING, 2019, p. 208), tal sistema agrícola agencia sua expansão reproduzindo imagens fractais a partir de um mesmo molde. Ignorando quaisquer diferenças biogeomorfológicas, a monocultura produz conceitualmente uma terra nullius impondo fim a todo tipo de relação (humana e extra-humana) então existente (TSING, 2019, p. 186). Mais uma vez, as palavras de Heleno Bento são importantes, e eu o cito novamente:

O algodão dava a renda em dinheiro, inclusive deixou muita coisa na nossa região Nordeste, nós sentimos falta pela perda do algodão, porque nós atribuímos muito a questão da degradação do ambiente ao algodão, 
mas não foi o algodão, foi a forma que foi trabalhado o algodão. Ele até poderia recuperar áreas que hoje estão devastadas, porque ele é uma árvore que produz muita matéria orgânica. Mas a ganância do povo era muito grande, então abriam muitas áreas, queimavam, não tinha um cuidado com a terra, e foi o que veio acarretar a degradação. Mas o algodão em si é uma planta que era cultivada aqui na região do Seridó desde os indios, que era o algodão mocó que mais tarde passou a ser chamado de algodão arbóreo. Foi quando as empresas inglesas se interessaram pela sua lã, porque era resistente e de um branco muito intenso. Então veio se propagar o plantio em grandes escalas, porque elas ofereciam para os proprietários que eram mais abastecidos financeiramente produzirem.

Esses relatos apontam para um importante corolário para ter como horizonte quando nos dedicamos ao estudo das relações multiespecíficas e, especialmente, quando lidamos com paisagens devastadas, uma vez que, nesses casos, tal situação se apresenta com explícita evidência. A saber: não estabelecer distinções entre a dominação humana e a exploração da natureza. Com efeito, a máquina da plantation pode ser tomada como um caso exemplar da articulação desses dois planos em homologia. Paralelamente à imobilização da mão de obra gerada por meio do trabalho degradante (PALMEIRA, 1977; HEREDIA, 1988), ela devastou toda a vegetação nativa para a introdução de uma só espécie ${ }^{13}$. Literalmente, ela estabelece uma monocultura, não apenas no plano infraestrutural, no que concerne morfologia dos sistemas de manejo do solo, mas também impedindo que outras formas de pensar a existência possam surgir em seu seio, mantendo a possibilidade da diferença submersa, termina afetando igualmente as representações sociais, de modo a imobilizar qualquer variação possível na superestrutura ${ }^{14}$. Nesse contexto, “[...] o que está em jogo é em suma um patrimônio de territórios-natureza e de informação biológicosocial, de patrimônios técnicos e de riqueza metafísica, de uso de corpos e de movimentos" (ALMEIDA, 2016, p. 25). Aqui, natureza e cultura se entrelaçam e a ecologia se emaranha com a luta de classes, pois a devastação afetou tanto a dimensão cultural quanto natural.

Esse movimento de modernização agrícola não emergiu como um raio em um céu azul, para estabelecer seu domínio, foi preciso sufocar o sistema agrícola tradicional até então vigente. Este último, durante esse período não foi suprimido por completo, mas se manteve de modo 
limitado reservado apenas aos pequenos roçadinhos (GARCIA JR. 1989; WOORTMANN; WOORTMANN, 1997) dos moradores que insistiam em manter seus cultivos sazonais de subsistência, aguardando, por assim dizer, uma ecologia (GUATTARI, 2012) favorável para se atualizar. Fato que veio acontecer apenas após a irrupção de um acontecimento surpreendente, a saber, o aparecimento de um inseto nunca antes visto na região, o bicudo (Anthonomus grandis).

\section{O Bicudo e a Contracolonização do Mundo da Plantation}

Em 1983, mais precisamente, é quando se tem as primeiras notícias dessa "praga" dotada de forças avassaladoras e bastou apenas quatro anos para o bicudo se disseminar entre Pernambuco, Paraíba e Rio Grande do Norte, decretando por completo o fim da então estrutura social que gravitava entorno das plantations de ouro branco. Em 1987, já não existiam mais condições para o cultivo do algodão e todas as usinas de beneficiamento já haviam paralisado por completo suas atividades. Segundo os agrônomos José Miranda e Sandra Rodrigues, que se propuseram a contar a "História do Bicudo no Brasil": "Não existiu até hoje, porém, praga de maior risco e habilidade para prejudicar a produção de fibras que o bicudo-do-algodoeiro (Anthonomus grandis) [...]", de modo que "[...] a história da cotonicultura no Brasil pode ser dividida em dois momentos: antes e depois da introdução do bicudodo-algodoeiro em terras brasileiras, tal foi o impacto que esta espéciepraga causou na atividade". (MIRANDA; RODRIGUES, 2015, p. 10).

Para muitos agricultores, como seu Inácio Garcia, o fim da exploração e da sujeição à qual estavam submetidos os agricultores familiares camponeses se deu graças à intrusão desse inseto, como ele me relatou no alpendre de sua casa:

Veio um tal de um inseto chamado bicudo, que deu a liberdade a todo agricultor, o algodão caiu, ninguém quis nem mais de graça, foi ele quem tirou o pobre da escravidão. Ai pronto, acabou-se a escravidão, e foram atrás de remissão, atrás de outra forma, cortar uma lenha, trabalhar um dia aqui outro acolá, essa coisa. [...] Hoje todo mundo anda vestido, o bicudo acabou com tudo, e ninguém quer mais plantar, porque se plantar o bicudo come. 
Como hoje não há mais plantações de algodão por essa região, o bicudo já não mais pode ser observado na textura da paisagem, de modo que não tive a oportunidade de me deparar com o inseto em campo e observar tanto a relação com sua espécie hospedeira, o algodão, quanto com os humanos. Porém, o mesmo Inácio me ofereceu uma detalhada descrição, tanto de sua morfologia quanto de seu comportamento em meio às plantações.

o bicudo é um inseto pequeno, mas tem um bico na cabeça, um ferrão bem grande que ia e furava o casulo. Naquela furada ele chupava a água do casulo e já transmitia a ova dentro para tirar os filhotes. Aquele casulo já não abria mais, ficava duro, seco, quebrava, e quando quebrava estava cheio de bicudo dentro. Agora tinha que era demais, a EMBRAPA ainda bateu em cima, arrumou inseticida, mas não teve jeito não, ele venceu. Tirou o pobre da escravidão.

A razão para sua emergência, contudo, é fonte de controvérsia, tratando-se de uma espécie originária da América Central, existem diferentes hipóteses sobre seu surgimento no semiárido brasileiro. A literatura não consegue traçar com precisão o percurso que levou o bicudo do México, local onde ele foi registrado pela primeira vez entre 1831 e 1835 ao interior do sertão paraibano. Contudo, essa espécie já havia se disseminado nos Estados Unidos quase um século antes de chegar no Brasil (sua primeira aparição data de 1892 no Texas), causando danos igualmente devastadores a cotonicultura local, e de onde se especula como hipótese mais provável a origem de sua migração (LUKEFAHR; BARBOSA; BRAGA SOBRINHO, 1984). Na América do Sul, o bicudo foi encontrado pela primeira vez em 1949 na Venezuela e, posteriormente, em 1950, na Colômbia.

No Brasil, seu aparecimento, tanto nos registros orais de agricultores familiares quanto na literatura científica, data de 1983. Esta última fonte afirma ainda que quase, paralelamente, foram coletados exemplares nas plantações de algodão em São Paulo e na região do semiárido. O primeiro artigo publicado sobre o inseto no Brasil data deste mesmo ano, logo no instante de sua aparição. O autor Octavio Nakano (1983) com título de "Bicudo: a praga mais importante do algodão" evidenciava o tom de preocupação dos agrônomos que já destacavam sua rápida disseminação. Os pesquisadores parecem concordar com o fato de que 
o inseto teria chegado ao Brasil pelo céu, trazido no interior de um avião. Porém, no que tange à disseminação do bicudo no país, duas hipóteses se contradizem, e eu cito mais uma vez Miranda e Rodrigues:

[...] a primeira considera que os insetos detectados no Nordeste teriam sido transportados em caroços produzidos em São Paulo, e que foram semeados para cultivo nas áreas nordestinas (Barbosa \& Lukefahr, 1983; Bastos et al., 2005); outra hipótese considera que as ocorrências em áreas extensas e distantes de populações em níveis elevados indicam terem ocorridos duas introduções distintas (Degrande et al., 2004; Degrande, 2006; Azambuja \& Degrande, 2014). (MIRANDA; RODRIGUES, 2015, p. 14)

A versão que contam os agricultores que viveram a emergência do bicudo e a derrocada do algodão se aproxima bastante do discurso científico nesse ponto. Para eles, o responsável pelo aparecimento do inseto foram os movimentos de melhoramento genético-científico e a introdução de sementes exóticas por parte das empresas de assistência rural. Essas sementes modernas, consideradas mais produtivas, das quais os agricultores não tinham conhecimento até então, não vieram sozinhas; meus amigos suspeitam que o referido inseto veio em sua companhia. Como me narrou Dóia:

o bicudo apareceu por causa de uma semente que veio de fora, era desconhecida e 'eles' [extensionistas] diziam que produzia muito, mais do que a semente que a gente tinha. Mas foi o contrário, em vez de produzir acabou foi o que tinha.

Posição também corroborada por outro agricultor, Cleonaldo:

Eu acho que o bicudo chegou através dessas importações de sementes que vem de fora, porque aqui nós não tínhamos este inseto.

Contudo, ao dissertarem sobre as razões que provocaram sua emergência, uma nova camada é adicionada à narrativa, introduzindo efetivamente a dinâmica política no cenário. Uma interpretação adotada por muitos agricultores é de que se tratou de um caso de sabotagem motivada pela competição internacional, pois justamente neste mesmo momento o algodão sintético americano ganhava força e disputava mercado com o algodão brasileiro (lembremos que, ao que parece, 
curiosamente, o bicudo veio dos Estados Unidos). Hipótese essa inclusive considerada pelo historiador Douglas Araújo (2003) em sua tese de doutorado, na qual o autor narra o que chama de "A morte do sertão antigo no Seridó." Essa dobra torna a história ainda mais interessante, pois o mesmo ator é paralelamente aliado de práticas americanas de sabotagem nas disputas geopolíticas do capitalismo e responsável por possibilitar famílias de pequenos agricultores familiares a se libertar da opressão que a plantation impunha ${ }^{15}$, possibilitando uma nova atualização do conhecimento tradicional local a partir de uma difusa descentralização fundiária por ele promovida.

A vitória do bicudo sobre a monocultura não se deu sem tentativas de resistir a sua força devastadora, a Empresa Brasileira de Pesquisa Agropecuária (EMBRAPA) logo iniciou várias tentativas de combater a praga. Sem sucesso no controle químico, tentaram, por meio de cruzamentos genéticos, alterar a época de floração do algodão, para que não coincidisse com a época de reprodução do bicudo. Com resultados pouco efetivos, a EMBRAPA desenvolveu ainda uma nova variedade de algodão, agora "colorida", esperançosa de que essa pudesse ser mais resistente ao inseto.

Sobre o algodão "colorido" me parece oportuno sublinhar como os agricultores receberam a referida inovação técnica: Heleno Bento me contou que, em meio à infestação do bicudo, começou a se disseminar um comentário de que chegaria uma nova variedade de algodão, a "colorida". Ele matutava, tentando especular de que se tratava essa novidade; ficou esperançoso. Pensou que a roça seria tomada por uma diversidade de tons de azul, amarelo, vermelho... como se eles já saíssem dos jardins tingidos. Foi uma decepção e tanto para esse agricultor velho ${ }^{16}$ quando viu o algodão colorido e se deu conta de que a única cor era um marrom que ele classificava como xoxo. Percebeu também que não se tratava de uma novidade tão grande; pois, mesmo antes do bicudo, em meio aos pés de algodão sadios, por vezes, surgia um algodão desse tipo, que, por sua vez, era imediatamente descartado.

Mas como dizem meus amigos, essas tentativas não tiveram muito futuro, todos os projetos de combater o inseto fracassaram e o bicudo terminou vencendo a guerra contra a plantation. Minúsculo, 
de aproximadamente sete milímetros, o bicudo teve uma ação de magnitude revolucionária e, em poucos anos, impôs fim ao cultivo de algodão, desmantelando esse sistema de dominação, contracolonizando, porque nunca foi colonizado, para lembrar Antonio Bispo dos Santos (2015), a agricultura científica. Foi uma ingenuidade pensar que excepcionalmente os humanos detinham o poder de transformação da paisagem. Parafraseando Marx (1852, p. 25), “os homens fazem a sua história, mas não a fazem como querem", e não o fazem porque a história dos homens é a história das relações multiespécies ${ }^{17}$. Enquanto a agricultura moderna por um tempo pensou-se capaz de imprimir sua imagem na paisagem e domesticar a natureza, terminou ela desarticulada pelo bicudo. Com efeito, embora por vezes possa parecer, os humanos nunca estão completamente no controle. O argumento de Nills Bubandt (apud HARAWAY et al., 2015, p. 545) ainda que em outro contexto é útil para nossos fins: “[...] esta não é de maneira alguma uma história da maestria humana, é uma história de consequências não intencionais e decadência"18.

Esse não é um fato isolado, já é de conhecimento na literatura acerca de sistemas agroalimentares os riscos e efeitos destrutivos que a monocultura com sua baixa diversidade de germoplasma pode ocasionar, dada a homogeneidade genética gerada nesses ambientes e a consequente vulnerabilidade em termos de defesa a patógenos. Talvez o caso mais exemplar seja a peste que assolou os cultivares de batatas na Irlanda durante século XVII, obrigando milhões de pessoas a optar entre as escolhas infernais de sucumbir a fome ou emigrar. No Brasil, outro caso conhecido é o da Vassoura-de-Bruxa (Moniliophtera perniciosa), doença provocada por um fungo que vem acometendo de modo igualmente avassalador as plantações de cacau na Bahia. Outro fato semelhante é também narrado na pesquisa de Machado (1975) acerca da chamada Fordolândia e a frustrada tentativa de introdução de uma monocultura de seringa na Amazônia no início do século passado, quando um fungo se aproveitou da proximidade das árvores e impediu a prática de exploração. O que essas contínuas histórias de fracasso das plantations parecem sugerir é que essas pragas e espécies invasoras não são elementos exógenos, mas parte constitutiva de sua existência 
(ainda que não estejam necessariamente previstas nos modelos), na medida em que essa ecologia favorece a emergência desses modos de habitabilidade (TSING, 2019, p. 218).

Nesse sentido, a história da relação do bicudo com o algodão é um caso interessante de ser mencionado, pois a literatura indica que a associação entre o inseto e a planta veio ocorrer apenas recentemente, há menos de 150 anos. Nos primeiros registros entomológicos do besouro, não é sequer mencionada sua espécie hospedeira, e uma vez que os europeus chegaram à América no século XVI, e os astecas naquele momento já produziam algodão em quantidade significava, é pouco provável também que ele habitasse essa planta e passasse despercebido tanto pelos nativos quanto pelos colonizadores que tinham interesse comercial na espécie. No século XIX, quando há uma grande transferência de germoplasma entre o México e os Estados Unidos, já com a botânica e a entomologia em estágio avançado, também não se encontra qualquer menção à relação do bicudo com o algodão.

Essas histórias são contadas por Lukefar, Barbosa e Braga Sobrinho (1984), os autores sugerem que o bicudo passou a parasitar o algodão apenas no final do século XIX, quando, por ocasião da Guerra Civil Americana e do bloqueio de importações por parte da Inglaterra da produção dos confederados, o México expande suas plantações de algodão em virtude dos altos preços do mercado. Com isso, as monoculturas encontram o bicudo, que, até então, habitando apenas espécies do gênero Hampea e sem incidência significativa, tem contato com o Gossypium (gênero botânico ao qual pertence o algodão), encontrando nas plantations um verdadeiro banquete e um convite para sua reprodução ilimitada. Sem respeitar as fronteiras estabelecidas pelos Estados Nacionais, o bicudo segue as fibras e migra rumo ao norte para o chamado "cinturão do algodão", localizado no Sul dos Estados Unidos, desmantelando as monoculturas e causando significativos efeitos nas relações sociais locais, exercendo influência, por exemplo, no sistema educacional, fato que pode ser constatado a partir do aumento exponencial de matrículas nesse período (BAKER; BLANCHETTE; ERIKSSON, 2018) e na migração de populações negras para o norte, graças à liberação da mão de obra que o inseto gerou (HIGGS, 1976). 
Eu gostaria de me deter um pouco mais sobre esses dados, pois mais uma vez a história se torna complexa. Com efeito, antes de praga, o bicudo é um sobrevivente. Um bloqueio internacional motivado pela permanência da escravidão no Sul dos Estados Unidos, leva seu vizinho México a se aproveitar da conjuntura econômica e reproduzir esse sistema agrícola em seu território. Então, ecologias nativas são devastadas para introdução da plantation, e, dentre toda redução da biodiversidade provocada pela monocultura que se expande, um inseto consegue se adaptar e sobreviver a esse ambiente estranho. Só que, de maneira surpreendente, ele encontra no algodão um nicho em condições mais favoráveis que as anteriores, que o permite desvincular-se de suas relações prévias, proliferando-se praticamente sozinho, sem espécies que pudessem competir ou predá-lo. A partir de então, migrando para outros ambientes, o bicudo coevoluiu com a planta de tal modo que se tornou capaz de habitar ecologias com características distintas daquelas nas quais tinha ocorrência. Agora companheiro, parasita e dependente, três das quatro fases de sua vida (ovo, larva, pulpa, adulta) se dão efetivamente dentro das flores de algodão e, apesar de sua capacidade de alimentar-se de outras espécies em contextos de escassez e situações de entressafra, sua reprodução se torna condicionada pela planta, na medida em que só é capaz de efetivar-se em meio as suas fibras (SUJII; PIRES, 2015, p. 60-61).

Pronto, mas se por um lado o bicudo impôs fim a todo um mundo (o mundo do Um, da monocultura), ele mesmo foi responsável por abrir novas possibilidades de gerar outros mundos, por meio da devastação sobre a devastação da plantation, o inseto permitiu, através do vazio que deixou, a regeneração da vida por outros modos. Não seria o caso também de tentar romantizar a história e pensar que, com o fim das plantations de algodão, houvesse cessado por completo os movimentos de dominação humana e exploração da natureza. Ao contrário, no semiárido, após o fim do ouro branco, outros movimentos de extração monetária da terra tão violentos e, até então menos expressivos, ganharam força. Refiro-me aqui à atividades como a cerâmica para fabricação de tijolos, a mineração de pedras de baixo valor econômico, como a calcita, a scheelita, a columbita, entre outras, além da mais 
recente intrusão de um complexo de campos eólicos, cujos efeitos ainda me parecem difíceis de serem tratados analiticamente.

\section{Uma Fenda Aberta para a Regeneração: outros mundos possíveis}

Contudo, eu gostaria de concentrar o restante desta reflexão em outra fenda aberta pelo bicudo, especialmente no que diz respeito à mais recente atualização dos sistemas agrícolas tradicionais ${ }^{19}$ efetuada por esses camponeses que se autodenominam "agricultores experimentadores". Essas práticas se orientam por princípios diametralmente opostos àquela da monocultura de algodão anteriormente mencionada, ao contrário, todo o trabalho de meus amigos no manejo do solo é tentar estabelecer uma composição criativa junto às forças que as diferentes maneiras de existir extra-humanas carregam em seus respectivos movimentos.

Experimentam diferentes meios de cuidar das plantas e dos animais, estabelecendo teias de relações alternativas àquela dominante na região, nas quais se compartilham, além de sementes, tecnologias e experiências agrícolas, criadas e testadas por eles próprios no cotidiano da vida na roça. Um conhecimento que é sempre particular, mas que pode ser compartilhado e reapropriado por outros agricultores com certo grau de variação e adaptação conforme cada contexto e suas respectivas singularidades biogeomorfológicas ${ }^{20}$. Isto é, de acordo com o tamanho de cada terreno, as qualidades nutricionais de cada solo, o relevo, o clima e a quantidade de água que é possível armazenar em cada território.

Frente à natureza indomesticável, os agricultores experimentadores não objetivam submeter a terra à sua pura vontade como o faz a plantation, nem plantam uma quantidade maior do que podem aguar. Ao contrário, preferem compor com a vida já existente, se articulando aos fluxos de chuva que fazem toda vida gravitar ao seu redor. É a intensidade da precipitação pluviométrica que cai em determinado período, acrescida da capacidade de armazenamento dela, que definirá o tamanho do plantio e as espécies cultivadas. Se os regimes de estiagem são incertos e prolongados, selecionam-se as espécies arbóreas mais resistentes aos longos períodos de baixa pluviosidade. Perder uma árvore 
ou um animal para a seca é um acontecimento desgraçado e pode ser considerado um desmantelo grande, portanto, a escolha de espécies nativas sempre supera as exóticas, estas quando bem adaptadas ao clima são introduzidas se misturando aquelas já existentes na medida em que se considera que elas podem contribuir positivamente na revitalização de uma paisagem devastada ${ }^{21}$, trazendo a vida de volta à terra ${ }^{22}$.

O que me parece também impressionante é o fato de que, mesmo após mais de meio século de dominação da paisagem por parte de um sistema agrícola que por meio de uma biopolítica determinava as culturas que naquele espaço poderiam existir, tenha havido sucesso nas estratégias dos agricultores tradicionais locais em preservar a diversidade dos cultivares sazonais característicos da região. Apenas durante meu campo de 2018 com um pequeno grupo de agricultores, registrei o número de 21 variedades de feijão macassar (Vigna unguiculata) ${ }^{23}$, e 15 de milho ${ }^{24}$, sendo possível tanto que existam mais variedades do que consegui catalogar, dado o reduzido tamanho de minha amostragem, quanto que no passado houvesse existido ainda mais variedades que no presente, considerando o grau de violência que a plantation imprimia por meio de seu poder ${ }^{25}$. Como me disse Seu Heleno sobre suas variedades cultivadas de milho evocando a ancestralidade das práticas de conservação de coleções botânicas:

Essas espécies que a gente trabalha aqui são de milho crioulo. São famílias que vêm conservando essas sementes desde os antepassados. Do pai, dos avós, esse milho é muito adaptado à nossa região, à nossa terra, ao clima.

Essas variedades de milho e feijão mencionadas podem pertencer ainda a duas qualidades diferentes relativas ao tempo e à intensidade da safra, a saber: ligeiro ou tardão. A primeira, com floração prevista para 60 dias e com ciclo vegetativo curto, na maior parte das vezes, é semeada logo após a primeira invernada ${ }^{26}$ para garantir a colheita imediata. Já as sementes de qualidade tardão, costumam começar a safrejar apenas com cerca de 90 dias, mas, como dizem os agricultores, dão com mais força ${ }^{27}$, oferecendo a colheita por um período mais extenso. O feijão dessa qualidade permanece botando enquanto há umidade no solo, e inclusive ouvi que no passado, quando o inverno era melhor do que é hoje, por vezes, ele atravessava um ciclo anual inteiro gerando 
vagens. É necessário ainda mencionar, tanto a diversidade de modos com que esses cultivares são realizados, sendo possível tanto seu plantio solto, quanto consorciado (este último, podendo ser realizado por meio de diferentes combinações), além da coexistência nesses jardins de outros cultivares, a saber, a melancia e o jerimum (este também com duas qualidades distintas, a saber: caboclo e de leite), igualmente importantes na alimentação local.

Conhecidas popularmente como "sementes da paixão", essas variedades de milho e feijão constituem um valioso recurso agrobiológico. Conservadas tradicionalmente e continuamente replantadas no tempo do inverno, são adaptadas à ecologia local porque mantêm um vínculo histórico com o ambiente. Tal diversidade, parece se configurar como uma estratégia local de segurança alimentar (EMPERAIRE, 2011, p. 136), pois ao contrário da monocultura, a diversidade favorece a resistência a pragas e diminui os riscos de colapso agrícola. Dado que determinadas variedades são mais resilientes enquanto outras se caracterizam por uma produtividade superior, caso algum infortúnio venha assolar as plantações, a diversidade genética garante que a safra não se perca por completo ${ }^{28}$.

Essa dedicação à coleção se estende a todo gênero botânico. Cada agricultor tem em sua residência um banco de sementes próprio, no qual armazena as espécies por ele cultivadas para quando necessário semeá-las. Talvez o caso mais exemplar desse tipo de cuidado seja Judivan, agricultor que, em seu pequeno sítio de menos de um hectare, guarda 85 garrafas com diferentes sementes, anualmente renovadas para que não percam seu teor germinativo. Como ele me contou de maneira objetiva:

Isso é para quando eu precisar das sementes, eu ter, e não perder as sementes nativas, medicinais. Por exemplo, se está em extinção o mastruz (Dysphania ambrosioides) na horta, semeio e não perco a semente. Esse ano faltou a crista de galo (Celosia cristata), aí, eu semeei.

Um encontro com outro agricultor é também sempre uma oportunidade para levar para casa algumas plantas novas. Quando acompanhava meus amigos visitando outros agricultores, sempre os observava atentos a algum vegetal que pudesse lhes interessar. 
Quando os indagava acerca das plantas por eles cultivadas, terminava escutando propriamente a história destas. Uma planta denota sempre uma continuidade com alguma outra coisa estabelecida por uma relação. Como ela veio parar ali? Quem lhe presenteou? Ou, onde foi coletada? Quando uma planta cultivada é cortada ou corre o risco de morrer, as pessoas também sofrem porque lhe dedicaram um afeto desde o momento em que as semearam ou coletaram. Acerca das agricultoras Wajãpi, nos diz Joana Cabral de Oliveira (2016, p. 119): "[...] toda mulher lembra com precisão quem lhe deu a variedade e qual sua procedência $[\ldots]$ ", afirmação válida também para as pessoas com quem convivi. Além disso, o compartilhamento de plantas estabelece como efeito prático uma rede de segurança genética, pois, caso uma semente cultivada se perca, uma vez que ela tenha sido repassada no passado, é possível recuperá-la com a pessoa que recebeu.

\section{Considerações Finais}

Nesta ocasião, procurei centrar meu argumento em torno da comparação entre dois sistemas agrícolas situados no tempo, e inspirado no que Tania Stolze Lima (1999) realizou em outro contexto, busquei de algum modo oferecer uma teoria etnográfica da plantation na região do Seridó. Ao destacar as consequências não intencionais das tentativas de controle humano e trazer para primeiro plano da narrativa um caso no qual um inseto surpreende e frustra projetos modernos de domesticação da paisagem, meu objetivo foi demonstrar a vulnerabilidade intrínseca à qual as monoculturas estão submetidas, bem como a necessidade da permanência de uma contínua relação de mutualismo amistosa com outros viventes para que a vida tal como conhecemos se mantenha em homeostase.

Submerso ao meu argumento, há o confronto entre dois sistemas agrícolas que podem ser compreendidos como modos distintos de estabelecer relações com o mundo. O conhecimento tradicional dos agricultores experimentadores com sua criativa composição da vida, na qual se aproveitam as potencialidades telúricas, e a agricultura inspirada nos padrões científicos modernos, cujo meio é a dominação da paisagem por meio da imposição de um mundo, e o fim, a extração de recursos 
monetariamente quantificáveis da terra. Esse procedimento aponta para os efeitos que os encontros pragmáticos orientados por determinadas ontologias (ALMEIDA, 2013) geram na textura das paisagens.

Contar essas histórias de devastação e regeneração, acredito, nos permite cultivar artes de atenção no sentido propriamente educacional que a antropologia pode oferecer neste mundo desmantelado (INGOLD, 2019, p. 13), e nos ensinar a partir do conhecimento gerado por outros povos a perceber tanto os movimentos, em que a vida pode se fazer ou desfazer, quanto o fato de que o comportamento humano não é determinante, mas atua como variável importante na composição das ecologias que tornam possível a existência dos humanos e das demais espécies que habitam as paisagens.

Se aqui me detive em abordar a questão do ponto de vista diacrônico, não significa que tal batalha não ocorra também no nível sincrônico. Pois o desejo de manejar o solo apenas para dele extrair recursos monetários, combater a seca e integrar a economia do semiárido à produção capitalista nacional não teve seu fim (talvez nunca tenha) com a plantation, o que faz com que essa guerra entre dois modos de habitar o semiárido continue se dê por meio de outras frentes de luta. Como bem afirmou Heleno Bento, o fato de não mais ser possível produzir o algodão em larga escalar por meio de uma monocultura, não significa que não haja mais pessoas que tratem a atividade agrícola exclusivamente como um empreendimento econômico:

Tem pessoas que parecem agricultores, se parecem com o agricultor em todos os aspectos, se você olhar dirá que ele é um agricultor; mas se planta com ofim do trabalho, de colher para ganhar dinheiro, ele é um microagronegócio. A terra dele não é um espaço de sobrevivência, é um espaço comercial. 0 agricultor velho de verdade planta por prazer.

\section{Notas}

1 Versões preliminares deste artigo foram apresentadas no Encontro Sextas na Quinta, do Núcleo de Antropologia Simétrica e no VII React, no ST Conexões transversais entre a Antropologia da Ciência e Tecnologia e a Etnologia. Agradeço ao diálogo nessas duas oportunidades, em especial a Tania Stolze Lima, Marcio Goldman, Felipe Sussekind, Joana Cabral de Oliveira e Guilherme Sá, assim como os pareceristas desta revista pelas críticas e comentários que muito contribuíram na elaboração do argumento. Os equívocos e inconsistências, é claro, são de inteira responsabilidade minha. 
2 "In the slow ethics of encounter, we are not talking about concepts to be written about (as if from the outside), but rather about events to be participated in and shared, imaginatively and otherwise. Stories themselves have the potential to promote understandings of embodied, relational, contingent ethics. My slow writing is called forth by events within the living world, and it seeks to pull readers into ethical proximity with those events." Tradução livre.

3 O termo pode parecer estranho ao leitor no primeiro momento, uma vez que tal guerra que me proponho a descrever não se resume apenas aos conflitos propriamente bélicos, mas é travada sobretudo no plano ontológico. Trata-se em suma de uma "guerra silenciosa" em nome do progresso (CADENA, 2018) sobre o que pode ou não existir segundo distintas ópticas de mundo, no qual elementos extra-humanos (orgânicos e abióticos) recebem ou não estatuto significativo na no curso das ações (ALMEIDA, 2013). Ou ainda nos termos de Vandana Shiva (2003), uma luta entre sistemas de saber, cujo campo de batalha se constitui em essencial nas diferentes maneiras de estabelecer relações com a terra.

4 Mobilizo o conceito de 'indígena' no sentido que Eduardo Viveiros de Castro conferiu em 'Os involuntários da Pátria' (2016). Isto é, o indígena como pertencente a terra, originário da mesma, dotado de uma relação particular com esta. Este tratamento conceitual guarda ressonâncias com aquilo que Willian Balée (2008, p. 10) em outro momento caracterizou como "indigeneidade das paisagens", segundo o autor: "Indigeneidade é o estado ou qualidade de ser indígena. No meu uso do termo, se refere às maneiras tradicionais de conhecimento do mundo próprias de tradições culturais de pequena escala cujos sujeitos têm sido historicamente os alvos do colonialismo europeu e neo-europeu e, mais recentemente da globalização econômica".

5 Tal oposição entre estes dois modos de se relacionar com o bioma tem sido operacionalizada conceitualmente através do contraste entre "combate à seca" e "convivência com o semiárido". Essa disputa ontológica, por sua vez, tem como efeito implicações pragmáticas na textura da paisagem a partir da implementação de diferentes projetos e políticas públicas direcionadas para a região. Uma revisão minuciosa acerca do conflito entre essas metafísicas pode ser encontrada em Silva (2003).

6 Contabilizando um total de sete meses de trabalho de campo, distribuídos em diferentes períodos ao longo dos últimos anos, permaneci morando junto a esses agricultores na zona rural acompanhando suas respectivas rotinas no sítio. Tal pesquisa ainda em execução, pretende se estender também durante o doutorado.

7 Emprego conscientemente o termo "amigos" por acreditar ter sido fiel à máxima etnográfica enunciada por Clifford Geertz (2014, p. 45): “[...] devemos encontrar amigos entre os informantes e informantes entre os amigos". Como lembra Goldman (apud NOGUEIRA; PIRES, 2012), o termo empregado para se reportar às pessoas com quem os antropólogos realizam suas pesquisas deve se adequar a especificidade de cada relação estabelecida; no meu caso, para escapar de expressões dúbias como 'colaboradores', 'interlocutores', ou mesmo o tradicional e policialesco 'informantes', preferi utilizar o termo 'amigos' para me referir às pessoas que me receberam em suas casas e permitiram que eu permanecesse morando com elas durante um período. Nesse contexto, poderia também utilizar 'professores' assim como Rose (2011) se referiu a seus companheiros aborígenes, na medida em que foi com essas pessoas que aprendi o pouco que sei. Não pretendo estender uma reflexão sobre o uso do termo na antropologia, embora acredite que ele mereça uma meditação própria 
em outro momento. Assinalo apenas que meu uso se aproxima da familiaridade inventada pelos gregos entre 'filosofia' e 'amigo da sabedoria', mencionada por Deleuze (1988). Com efeito, como ele afirma em entrevista a Clarie Parnet, "não é o amigo em si, mas a amizade como categoria, como condição para pensar". Em certa medida é lícito admitir que os pensamentos que exponho não são apenas meus, mas atravessados pelos ensinos de meus amigos e professores através e na companhia dos quais eu penso.

8 Penso não só junto com meus amigos, mas também com seu léxico, buscando de algum modo na tradução cultural corromper o português acadêmico com o português falado neste pedaço do semiárido, de modo que as palavras nativas quando mobilizadas virão sempre em itálico, e quando necessária glosa, acompanhadas de uma nota explicativa.

9 O substantivo 'seridó' pode gerar equívocos, pois pode se referir a três coisas distintas, mas que de algum modo, se emaranham. Além de ser uma espécie de algodão, Seridó é também o nome dado a uma grande região interestadual do semiárido na qual habitam a maioria dos agricultores com quem realizado pesquisa, onde não por acaso é o local de ocorrência e onde era cultivado a espécie de algodão com o mesmo nome, além de ser justamente o nome dado ao maior núcleo de desertificação da Paraíba situado nesta macrorregião, a saber: Núcleo de Desertificação do Seridó, esse último tem como uma das principais causas do atual estado de baixa biodiversidade, o cultivo de algodão no passado, além do corte de lenha para cerâmica industrial e pecuária extensiva (COSTA et al., 2009).

${ }^{10}$ Todos os relatos aqui reproduzidos me foram concedidos pelos próprios agricultores durante minha última estadia em suas residências no ano de 2018. A decisão de manter a identidade original das pessoas no texto se deve a uma escolha teórica de reconhecer a potência de suas formulações conceituais, de modo que é digno (para não dizer essencial), tratá-los como autores e explicitar a fonte destes relatos.

11 O termo é frequentemente mobilizado pelos agricultores para se referir ao algodão. A analogia ao garimpo não parece arbitrária, pois em ambos os casos o trabalho e a riqueza coletada são distribuídos de modo simetricamente inversos, para o trabalhador muito trabalho e pouca remuneração, enquanto o pouco (ou nenhum) trabalho realizado pelo patrão lhe gera uma volumosa renda. Correlacionada com a atividade de mineração através da expressão nativa, a agricultura ganha também contornos de extração, onde a única finalidade da referida é extrair da terra recursos monetariamente quantificáveis.

${ }^{12}$ Expressão nativa para desmatar.

13 Com origem nas colônias do Novo Mundo, a plantation operava inicialmente através da produção em larga escala, aliando monocultura, trabalho escravo e semeadura de espécies exóticas. Ao possibilitar o comércio intercontinental a partir da chamada acumulação primitiva, foi ela responsável por criar condições para a emergência da industrialização. Ainda que as contingências da história tivessem forçado sua transformação, permaneceu inalterada a mesma lógica no agronegócio contemporâneo, com o uso de mão de obra terceirizada de remuneração precária e produção direcionada principalmente para a exportação (TSING, 2015). Lembremos que justamente, uma das sugestões dos cientistas para nomear o atual momento de inflexão na história profunda do planeta caracterizado sobretudo pela catástrofe ecológica do presente (que tende a se agravar drasticamente no futuro), é batizar a nova época geológica de Plantationoceno. Ver Haraway (2015) e Haraway et al., (2016).

ILHA 
14 Acerca do sistema de dominação da plantation brasileira, o comentário de Otávio Velho (1976, p. 104) endossa este argumento: “[...] pode-se certamente dizer que fundamentalmente assiste-se no Brasil às manifestações de diferentes variedades (e variações) de um sistema de repressão da força de trabalho, incompatível tanto com a pequena produção independente quanto com a formação de um mercado de trabalho livre".

15 Aqui, inspirado na mitologia, a figura sociológica do trickster parece oportuna para pensar o bicudo. Frequentemente qualificado como um pregador de peças ambíguo, responsável por gerar uma desestabilização na estrutura, o trickster rompe a ordem, instaura o 'contraditório', 'confundindo' e 'enganando a todos', como menciona Beatriz Perrone-Moisés em sua glosa do termo. Com efeito, o bicudo parece ser um ator deste tipo, dotado de qualidades irredutíveis, sua ação promove o desequilíbrio nos dualismos estabelecidos impedindo qualquer codificação a priori. Aqui, as oposições rígidas como bem e mal, natureza e cultura, perdem seu valor explicativo, de modo que a ideia de ação, imanência e o valor incontestável do empreendimento etnográfico ascendem como uma perspectiva mais adequada para conferir inteligibilidade ao fenômeno.

${ }^{16}$ Velho aqui tem sobretudo valor de intensificador. Diz respeito a um agricultor verdadeiro nos termos locais. Outra expressão que poderia ser mobilizada aqui é de agricultor experiente, i.e. alguém que tem experiência, conhecimento.

17 Que por sua vez, para evitar algum equívoco, não significa que a história seja feita apenas das relações entre os organismos vivos. Vide o exemplo do papel do inverno russo nas guerras napoleônicas e na II Guerra Mundial ou mesmo em nosso contexto, a importância dos baixos índices pluviométricos e seus efeitos nos projetos de colonização, como mencionado no início deste artigo.

18 "is not a story of human mastery at all, it is a story of unintended consequences and decay." Tradução livre.

19 Laure Emperaire (2006, p. 4) define sistemas agrícolas tradicionais por: “Compartimentos que respondem a lógicas de produção, de uso de espaços diferenciados, de fatores limitantes biológicos ou ecológicos e a uma construção social e cultural; os sistemas locais de conservação de recursos fitogenéticos funcionam na base de redes, não institucionalizadas, porém muito eficazes, que lhe conferem uma forte resiliência. A circulação do germoplasma outorga à diversidade uma dimensão social e não só produtiva". A mesma autora chama atenção em outro momento para o fato de que, embora as relações estabelecidas entre humanos e plantas estejam sempre mediadas por uma dimensão cultural situada, pouco reconhecimento é conferido a este aspecto, tendo como ênfase analítica na maior parte dos casos apenas a sua capacidade produtiva (EMPERAIRE, 2011, p. 136).

${ }^{20}$ Como formulou Viveiros de Castro (2019), os agricultores familiares do semiárido não operam por meio da lógica do "modelo" como a plantation, e sim a partir do "exemplo", fato este que não contradiz com certa semelhança de práticas, uma vez que estas se orientam pelos mesmos princípios. Jorge Luan Teixeira ao tratar dos processos de geração e transmissão de conhecimentos relativos à caça entre agricultores no sertão cearense também reflete acerca das experiências. No que concerne ao modo com que este conhecimento é gerado e propagado, o autor chama atenção para seu caráter em eminente transformação. Se por um lado elas são localizadas e possuem relação direta com os encontros pragmáticos no cotidiano em cada contexto particular, por meio da fala as experiências são coletivizadas, Teixeira sublinha a importância da articulação intrínseca entre observar e narrar. Parece-

ILHA 
me que sobretudo neste último movimento, a criação apresenta seu vigor, pois o receptor da mensagem está quase sempre disposto a gerar alguma diferença, ainda que no nível infinitesimal, de modo a nunca reproduzi-la de maneira idêntica, mas se reapropriando por meio de um filtro que possa adaptar e readequá-la a um contexto diferente. Com efeito, as experiências parecem constituídas sobretudo pelo seu atributo transformacional, segundo Teixeira (2019, p. 246), “em perpétua alteração", em que a estabilização é apenas provisória e de natureza precária.

${ }^{21}$ Vide o exemplo do cajueiro (Anacardium occidentale), da grilicidia (Gliricidia sepium) e da moringa (Moringa oleifera), entre outros.

${ }^{22}$ Aqui vemos uma diferenciação entre o tratamento que os agricultores dão as espécies exóticas, e como as mesmas são introduzidas nos perímetros urbanos, onde mais uma vez ocorre a redução da diversidade para introdução de uma só cultura. Hoje, apenas duas espécies (ambas exóticas) compreendem quase a totalidade da vegetação urbana das cidades do Médio Sertão. A saber: a algaroba (Prosopis juliflora) e o nim (Azadirachta indica), este último, fonte de controvérsias no que tange a sua relação letal com as abelhas. Meus amigos não se furtam em ter no terreiro de suas casas tais espécies, inclusive pelo fato de que estas oferecem sombra além de matéria orgânica em abundância, mas como eles dizem, que futuro teria um campo tomado apenas por essas plantas?

23 'Curujinha', 'galanjão', 'manteiga', 'chifre de carneiro', 'costela de vaca', 'pingo d'água', 'sempre verde', 'das moça', 'pitiúba', 'branco', 'cancão', 'rabo de rato', 'rabo de tatu', 'ovo de guiné', 'xoxa bunda', 'canapú', 'jureminha', 'riograndense', 'quebra cadeira', 'caicó' e 'bala'.

24 'Jabatão', 'roxo', 'trigo', 'pontinha', 'alho', 'aracaju', 'catingueira', 'branco', 'pingoró', 'híbrido', 'vermelho', 'maçã', 'peba', 'anão' e 'cunha'.

${ }^{25}$ Em outra pesquisa realizada pela AS-PTA (Assessoria e Serviços a Projetos em Agricultura Alternativa), cujo objetivo era mapear estratégias de conservação de sementes tradicionais em seis comunidades do agreste, foram identificadas: "67 variedades de feijão de três espécies sendo, 28 variedades de feijão de arranque (Phaseolus unguiculata), 22 de feijão macassar (Vigna unguiculata) e 17 de fava (Phaselous lunatus)" (ALMEIDA; CORDEIRO, 2002, p. 46-47). Durante meu trabalho de campo, eu pouco ou nenhum contato tive com estas outras duas espécies de feijão, a não ser através de relatos em que elas apareciam como memória de tempos antigos, o que, por sua vez, se configura como forte índice da erosão genética. Acerca da redução de diversidade dos cultivares, embora não possa me estender no momento sobre o tema, é oportuno reproduzir a reflexão de Heleno Bento, na qual o agricultor elenca as principais razões que tiveram como consequência a perda de algumas variedades: “A respeito da diversidade de feijão que nós tínhamos no passado, existiram dois fatores que contribuíram muito para que nós perdêssemos essas variedades. Foram os períodos de estiagens muito prolongados e também o comércio e o poder econômico. Este último fez com que as pessoas façam essa seleção de feijão para que fique um feijão padronizado, para que fique de somente um tipo. Muito embora enquanto tivesse mais variedade de feijão, mas ele era saboroso para o consumo." Heleno menciona ainda uma variedade de feijão macassar em especial mais afetada pelas imposições do mercado nos sistemas agrícolas locais: “Este ['roxo'] foi o mais extinto por causa do comércio, porque não deixava uma cor muito bonita no feijão nem dava tanto, porém ele é mais resistente ao manhoso (Chalcodermus bimaculatus)". O agricultor se refere a um pequeno inseto que costuma atacar os feijões no período de safra provocando o adoecimento de suas vagens.

ILHA

v. 21 , n. 2, p. 65-95, dezembro de 2019 
${ }^{26}$ No léxico local, invernada se refere a chuva propriamente dita tal como inverno se refere ao período do ano onde se concentram com maior densidade os índices pluviométricos.

${ }^{27}$ Intensificador, i.e. dotado de um vigor reprodutivo mais intenso.

${ }^{28}$ Manuela Carneiro da Cunha (2017, p. 264) se referiu ao gosto pela diversidade como uma espécie de afinidade eletiva comum aos agricultores tradicionais. "I contend that Indigenous and local societies seem to overwhelmingly value diversity per se, for its own sake". Assim, não seria justo reduzir esse traço às necessidades objetivas de conservação de um reservatório de variedade genética ou para produção mecanismos de resistência a pragas, embora as experimentações e atividades de troca de sementes levem a esses efeitos práticos.

\section{Referências}

ALMEIDA, Mauro William Barbosa de. Caipora e outros conflitos ontológicos. Revista de Antropologia da UFSCar, São Carlos, v. 5, n. 1, p. 7-28, jan.-jun., 2013.

ALMEIDA, Mauro William Barbosa de. Desenvolvimento entrópico e a alternativa da diversidade. RURIS - Revista do Centro de Estudos Rurais, Campinas, SP, v. 10, n. 1, 2016.

ALMEIDA, Paula; CORDEIRO, Angela. Sementes da paixão: estratégia comunitária de conservação de variedades locais do semi-árido. Rio de Janeiro: AS-PTA, 2002.

ARAÚJO, Douglas. A morte do sertão antigo no Seridó:

o desmoronamento das fazendas agropecuaristas em Caicó e Florânia (1970-90). 2003. 364 f. Tese (Doutorado) - Programa de Pós-Graduação em História, Universidade Federal de Pernambuco, Recife, 2003.

BAKER, Richard B.; BLANCHETTE, John; ERIKSSON, Katherine. Longrun Impacts of Agricultural Shocks on Educational Attainment: Evidence from the Boll Weevil. National Bureau of Economic Research, [S.l.], 2018.

BALÉE, William. Sobre a indigeneidade das paisagens. Revista de Arqueologia, [S.l.], v. 21, n. 2, 2008.

DE LA CADENA, Marisol. Natureza incomum: histórias do antropo-cego. Revista do Instituto de Estudos Brasileiros, [S.l.], n. 69, p. 95-117, 2018.

DELEUZE, Gilles; PARNET, Claire. O abecedário de Gilles Deleuze. Realização de Pierre-André Boutang, produzido pelas Éditions Montparnasse, Paris. No Brasil, foi divulgado pela TV Escola, Ministério da Educação. Tradução e Legendas: Raccord. 1988. 
CARNEIRO DA CUNHA, Manuela. Traditional people, collectors of diversity. In: BRIGHTMAN, Mark; LEWIS, Jerome (ed.). The anthropology of sustainability: beyond development and progress. Basingstoke: Palgrave Macmillan, 2017. p. 257-272.

COSTA, T. C. et al. Análise da degradação da caatinga no núcleo de desertificação do Seridó (RN/PB). Revista Brasileira de Engenharia Agrícola e Ambiental, Campina Grande, PB, v. 13, Suplemento, p. 961974, 2009.

CUNHA, Euclides da. Os Sertões: Campanha de Canudos. Edição e prefácio, cronologia, notas e índice Leopoldo M. Bernucci. São Paulo: Ateliê editorial, Imprensa Oficial do Estado. Arquivo do Estado, 1905 [2001].

EMPERAIRE, Laure. História de plantas, histórias de vida: uma abordagem integrada da diversidade agrícola tradicional na Amazônia. In: KUBO, R. et al. (ed.). Anais do VI Symposium da Sociedade Brasileira de Etnobiologia e Etnoecologia. Porto Alegre, 2006. SBEE. 3: 189-198.

EMPERAIRE, Laure. Diversidade biológica e diversidade cultural. In: BARROS, José Márcio; KAUARK, Giuliana. Diversidade cultural e desigualdade de trocas: participação, comércio e comunicação. São Paulo: Itaú Cultural; Observatório da Diversidade Cultural, Editora PUCMinas, 2011.

GARCIA JR., Afrânio. Sul, o caminho do roçado. Estratégias de reprodução camponesa e transformação. São Paulo: Editora Marco Zero, 1989.

GEERTZ, Clifford. Nova luz sobre a antropologia. São Paulo: Zahar, 2014.

GUATTARI, Félix. As três ecologias. 21. ed. Tradução Maria Cristina F. Bittencourt; revisão da tradução Suely Rolnik. Campinas, SP: Papirus, 2012.

HARAWAY, Donna. Saberes localizados: a questão da ciência para o feminismo e o privilégio da perspectiva parcial. Cadernos Pagu, [S.l.], n. 5, p. 7-41, 1995.

HARAWAY, Donna et al. Anthropocene, capitalocene, plantationocene, chthulucene: Making kin. Environmental humanities, [S.l.], v. 6, n. 1, p. 159-165, 2015.

HARAWAY, Donna et al. Anthropologists are talking: about the Anthropocene. Ethnos, [S.l.], v. 81, n. 3, p. 535-564, 2016.

HEREDIA, Beatriz M. Alásia de. O campesinato e a plantation: a história e os mecanismos de um processo de expropriação. In: NEVES, Delma Pessanha. Processos de constituição e reprodução do campesinato no Brasil. São Paulo: Fundação Editora UNESP (FEU), p. 39-68, 1988 [2008]. 
HIGGS, Robert. The Boll Weevil, the Cotton Economy, and Black Migration 1910-1930. Agricultural History, [S.l.], v. 50, n. 2, p. 335-350, 1976.

HOLLIVER, Gabriel. “Tá bonito pra chover": agricultores experimentadores no semiárido da Paraíba. 2016. 58 f. Monografia (Graduação em Ciências Sociais) - Pontifícia Universidade Católica, Rio de Janeiro, 2016.

HOLLIVER, Gabriel. Agricultores experimentadores do semiárido paraibano frente ao desmantelo do mundo. 2019. $194 \mathrm{f}$. Dissertação (Mestrado em Antropologia Social) - Museu Nacional, Universidade Federal do Rio de Janeiro, Rio de Janeiro, 2019.

INGOLD, Tim. Antropologia: para que serve? São Paulo: Vozes, 2019.

KIRKSEY, S. Eben; HELMREICH, Stefan. The emergence of multispecies ethnography. Cultural anthropology, [S.l.], v. 25, n. 4, p. 545-576, 2010.

LAMARTINE, Oswaldo. Sertões do Seridó. Brasília, DF: Centro Gráfico do Senado Federal, 1980.

LIMA, Tânia Stolze. Para uma teoria etnográfica da distinção natureza e cultura na cosmologia juruna. Revista Brasileira de Ciências Sociais, [S.l.], v. 14, n. 40, p. 43-52, 1999.

LLOSA, Mario Vargas. A guerra do fim do mundo: a saga de Antônio Conselheiro na maior aventura literária do nosso tempo. Rio de Janeiro: Editora Francisco Alves, 1982.

LUKEFAHR, M. J.; BARBOSA, S.; BRAGA SOBRINHO, R. Aspectos históricos do bicudo do algodoeiro (Anthonomus grandis Baheman).

Embrapa Algodão-Documentos (INFOTECA-E), 1984.

MACHADO, B. Farquhar and Ford in Brazil: studies in business expansion and foreign policy. 491 f, 1975. Tese (Doutorado em História) Northwestern University Evanston, IL, 1975.

MARX, Karl. O 18 de Brumário de Luís Bonaparte. São Paulo: Boitempo, 2011 [1852].

MEDEIROS, Rondinelly Gomes. Mundo quase árido. Ilha Revista de Antropologia, Florianópolis, v. 21, n. 1, p. 21-37, 2019.

MIRANDA, José Ednilson; RODRIGUES, Sandra Maria Morais. História do bicudo no Brasil. In: INSTITUTO MATO-GROSSENSE DO ALGODÃO (IMAmt). O bicudo-do-algodoeiro (Anthonomus grandis Boh., 1843) nos cerrados brasileiros: Biologia e medidas. Cuiabá, MT: Editor técnico: Jean Louis Belot, 2015.

MIRANDA, José Ednilson; RODRIGUES, Sandra Maria Morais. Manejo do bicudo-do-algodoeiro em áreas de agricultura intensiva. Embrapa Algodão-Circular Técnica (INFOTECA-E), 2016. 
MORAIS, Lenildo Dias de. O Algodão Arbóreo no semiárido: o papel da pesquisa agropecuária pública no Vale do Piancó - estado da Paraíba. 2010. 106 f. Dissertação (Mestrado em Desenvolvimento Sustentável) Universidade de Brasília, Brasília, 2010.

NAKANO, Octavio. Bicudo: a praga mais importante do algodão.

Agroquimica, [S.l.], v. 21, p. 10-14, 1983.

NOGUEIRA, Silvia Garcia; PIRES, Flávia Ferreira. Antropologia Pós-Social, perspectivas e dilemas contemporâneos: entrevista com Marcio Goldman.

Campos-Revista de Antropologia, [S.l.], v. 13, n. 1, 2012.

OLIVEIRA, Joana Cabral de. Mundos de roças e florestas. Boletim do Museu Paraense Emílio Goeldi. Ciências Humanas, [S.l.], v. 11, n. 1, p. 115-131, jan./abr, 2016.

PALMEIRA, Moacir. Casa e trabalho: nota sobre as relações sociais na plantation tradicional. Contraponto, [S.l.], v. 2, n. 2, 1977.

ROSE, Deborah Bird. Wild dog dreaming: Love and extinction. Virginia: University of Virginia Press, 2011.

SANTONIERI, Laura Rodrigues. Agrobiodiversidade e conservação ex situ: reflexões sobre conceitos e práticas a partir do caso da Embrapa/ Brasil. 503 f, 2015. Tese (Doutorado) - Departamento de Antropologia Social, UNICAMP, 2015.

SANTOS, Antonio Bispo dos. Colonização, Quilombos Modos e Significações. Brasília, DF: INCTI, UnB, 2015.

SUJII, Edison Ryoiti Ednilson; PIRES, Carmen S. S. Plantas hospedeiras do bicudo-do-algodoeiro. In: INSTITUTO MATO-GROSSENSE DO ALGODÃO (IMAmt). O bicudo-do-algodoeiro (Anthonomus grandis Boh., 1843) nos cerrados brasileiros: Biologia e medidas. Cuiabá, MT: Editor técnico Jean Louis Belot, 2015.

SHIVA, Vandana. Monoculturas da mente: perspectivas da biodiversidade e da biotecnologia. Gaia, 2003.

SILVA, Roberto Marinho Alves da. Entre dois paradigmas: combate à seca e convivência com o semi-árido. Sociedade e Estado, [S.l.], v. 18, n. 1-2, p. 361-385, 2003.

SUSSEKIND, Felipe. Sobre a vida multiespécie. Rev. Inst. Estud. Bras., São Paulo, n. 69, p. 159-178, abr. 2018.

TADDEI, Renzo. Oráculos da chuva em tempos modernos, mídia desenvolvimento econômico e as transformações na identidade social dos profetas do sertão. In: MARTINS, Karla (org.). Profetas da chuva. Fortaleza: Tempo D'Imagem, 2006, p. 161-170. 
TEIXEIRA, Jorge Luan. Caçando na mata branca: Conhecimento, movimento e ética no Sertão Cearense. 2019. 458 f. Tese (Doutorado em Antropologia Social) - Museu Nacional, Universidade Federal do Rio de Janeiro, Rio de Janeiro, 2019.

TSING, Anna Lowenhaupt. Margens indomáveis: cogumelos como espécies companheiras. Ilha Revista de Antropologia, [S.1.], v. 17, n. 1, 177-201, 2015.

TSING, Anna Lowenhaupt. Viver nas ruínas: paisagens multiespécies no antropoceno. Edição Thiago Mota Cardoso, Rafael Victorino Devos. Brasília, DF: IEB Mil Folhas, 2019.

VELHO, Otávio Guilherme. Capitalismo autoritário e campesinato: um estudo comparativo a partir da fronteira em movimento. Rio de Janeiro: Difel, 1976.

VAN DOOREN, Thom; KIRKSEY, Eben; MÜNSTER, Ursula. Estudos multiespécies: cultivando artes de atentividade. Trad. Susana Oliveira Dias. ClimaCom, Campinas, Incertezas, ano. 3, n. 7, p. 39-66, dez. 2016. Disponível em: http://climacom.mudancasclimaticas.net.br/wp-content/ uploads/2014/12/07-Incertezas-nov2016.pdf. Acesso em: 2 fev. 2019.

VIVEIROS DE CASTRO, Eduardo. Os Involuntários da Pátria: aula pública durante o ato Abril Indígena, Cinelândia, Rio de Janeiro, 20 de abril de, 2016.

VIVEIROS DE CASTRO, Eduardo. On Models and Examples: Engineers and Bricoleurs in the Anthropocene. Current Anthropology, 2019. WOORTMANN, Klaas; WOORTMANN, Ellen. O trabalho da terra: a lógica simbólica da lavoura camponesa. Brasília, DF: Editora da UnB, 1997.

Recebido em 26/07/2019

Aceito em 13/11/2019

\section{Gabriel Holliver}

Doutorando em Antropologia Social pelo PPGAS-MN/UFRJ, mestre em Antropologia Social pelo PPGAS-MN/UFRJ e graduado em Ciências Sociais pela PUC-Rio. Integrante do Núcleo de Antropologia Simétrica e do grupo de pesquisa Natureza e Cultura: Sentidos da diversidade. Realiza desde 2015 pesquisa com populações camponesas no semiárido brasileiro, com ênfase em conhecimento tradicional, sistemas agrícolas e relações multiespécies.

Endereço profissional: Quinta da Boa Vista, s/n, São Cristovão, Rio de Janeiro, RJ. CEP: 20940-040.

E-mail: g.holliver@hotmail.com 